\title{
COVID-19 pneumonitis induced myocardial infarction and multi-organ failure: an ethical and clinical challenge.
}

\section{Susil Pallikadavath MBChB(hons)*, Zakariyya Vali MRCP, Sanjay S Bhandari PhD, Gerry P McCann MD}

Department of Cardiovascular Sciences, University of Leicester, and the NIHR Leicester Biomedical Research Centre, Glenfield Hospital, Leicester, UK.

*Corresponding author: Susil Pallikadavath, Academic Foundation Doctor, Department of Cardiovascular Sciences, University of Leicester and the NIHR Leicester Biomedical Research Centre, Glenfield Hospital, Leicester, UK, LE39QP.

Received Date: March 23, 2021; Accepted Date: April 16, 2021; Published Date: April $20,2021$.

Citation: S Pallikadavath, Z Vali, Sanjay S Bhandari, Gerry P McCann. (2021) COVID-19 pneumonitis induced myocardial infarction and multiorgan failure: an ethical and clinical challenge. Cardiology Research and Reports. 3(2): Doi: 10.31579/2692-9759/018

Copyright: (C) 2021 Susil Pallikadavath. This is an open-access article distributed under the terms of the Creative Commons Attribution License, which permits unrestricted use, distribution, and reproduction in any medium, provided the original author and source are credited.

\begin{abstract}
A 62-year-old man presented at the height of the first wave of the coronavirus disease 2019 (COVID-19) pandemic with hypoxia, multi-organ failure and haemodynamic instability. The electrocardiogram and echocardiogram were indicative of inferolateral ST segment elevation myocardial infarction. His hypoxia was initially thought to be driven by acute pulmonary oedema due to cardiac failure, but this was out-of-proportion to his left-ventricular function. This aroused suspicion of COVID-19 which he subsequently tested positive for. He was not deemed to be candidate for primary percutaneous intervention, intubation or mechanical ventilation; a difficult decision to make in a previously healthy, young patient. Clinical decisions were complicated by late presentation and hospital pressures related to the pandemic. Similar clinical scenarios are likely as we move into the next stages of the pandemic. Establishing clinical frameworks to help clinicians make these decisions, and identifying barriers to healthcare attendance, may be priorities for policy-makers.

Key words:COVID-19; myocardial infarction; medical ethics
\end{abstract}

\section{Introduction}

COVID-19 causing severe acute respiratory syndrome coronavirus 2 (SARS-CoV-2) has affected nearly every country in the world [1]. Cardiovascular complications of COVID-19 are increasingly well recognised and associated with poor prognosis [2]. The optimal strategy to manage patients with poor respiratory and cardiac function with multiorgan deterioration in COVID-19 remains unclear. Fluid therapy is a balance between adequate organ perfusion without worsening pulmonary oedema and volume load on the ventricles. Renal injury and hepatic dysfunction are also emerging complications of COVID-19 [3]. Renal dysfunction, in the form of acute kidney injury (AKI), secondary to sepsis is well known [4]. Whether the mechanism of AKI in COVID-19 follows the same pathophysiological process related to haemodynamic shock and acute tubular necrosis is unclear [3].

\section{Case presentation}

A 62-year-old male was admitted at the height of the first wave of COVID-19 with a two-day history of dyspnoea and tachypnoea Investigations revealed severe hypoxia and multi-organ compromise (Table 1). Admission ECG was consistent with an inferolateral STelevation myocardial infarction (MI) with posterior involvement (Figure 1). Bedside echocardiogram revealed moderate left ventricular dysfunction and severe right ventricular dysfunction (Figure 2). Hepatic and kidney damage were also observed (Table 1). Bilateral pulmonary infiltrates were noted on the initial CXR performed on admission and attributed to pulmonary oedema (Figure 3 ).

\begin{tabular}{|l|l|l|l|}
\hline Selected blood tests glomerular filtration rate* & Admission & Day two & Day three \\
\hline $\begin{array}{l}\text { Estimated } \\
\left(\mathrm{mL} / \mathrm{min} / 1.73 \mathrm{~m}^{2}\right)\end{array}$ & & 34 & 41 \\
\hline Creatinine (umol/L) & 204 & 186 & 157 \\
\hline Alanine aminotransferase (iu/L) & 836 & 894 & 459 \\
\hline Alkaline phosphatase (iu/L) & 190 & 184 & 221 \\
\hline International Normalized Ratio & 1.3 & 1.3 & 1.4 \\
\hline Troponin-I (ng/L) & 10,582 & 8,418 & 3,669 \\
\hline Vital signs & & & 35 \\
\hline Respiratory rate (breaths per minute) & 36 & 44 & \\
\hline
\end{tabular}




\begin{tabular}{|l|l|l|l|}
\hline Oxygen saturations (\%, oxygen therapy) & 78, no oxygen & $\begin{array}{l}87, \quad \text { CPAP } \quad 70 \% \\
\text { inspired air }\end{array}$ & 90, CPAP 15L \\
\hline Blood pressure (systolic mmHg/diastolic mmHg) & $90 / 73$ & $105 / 80$ & $104 / 73$ \\
\hline Heart rate (beats per minute) & 115 & 114 & 108 \\
\hline
\end{tabular}

Table 1: Selected blood tests and vital signs on admission, day two and day three.

Hepatic and renal dysfunction is seen to accompany poor oxygen saturations and elevated troponin-I on admission. Mild improvements are seen in hepatic and renal blood markers. Respiratory function shows mild improvements on continuous positive airway pressure oxygen therapy.

*eGFR as calculated by the Modification of Diet in Renal Disease (MDRD) equation

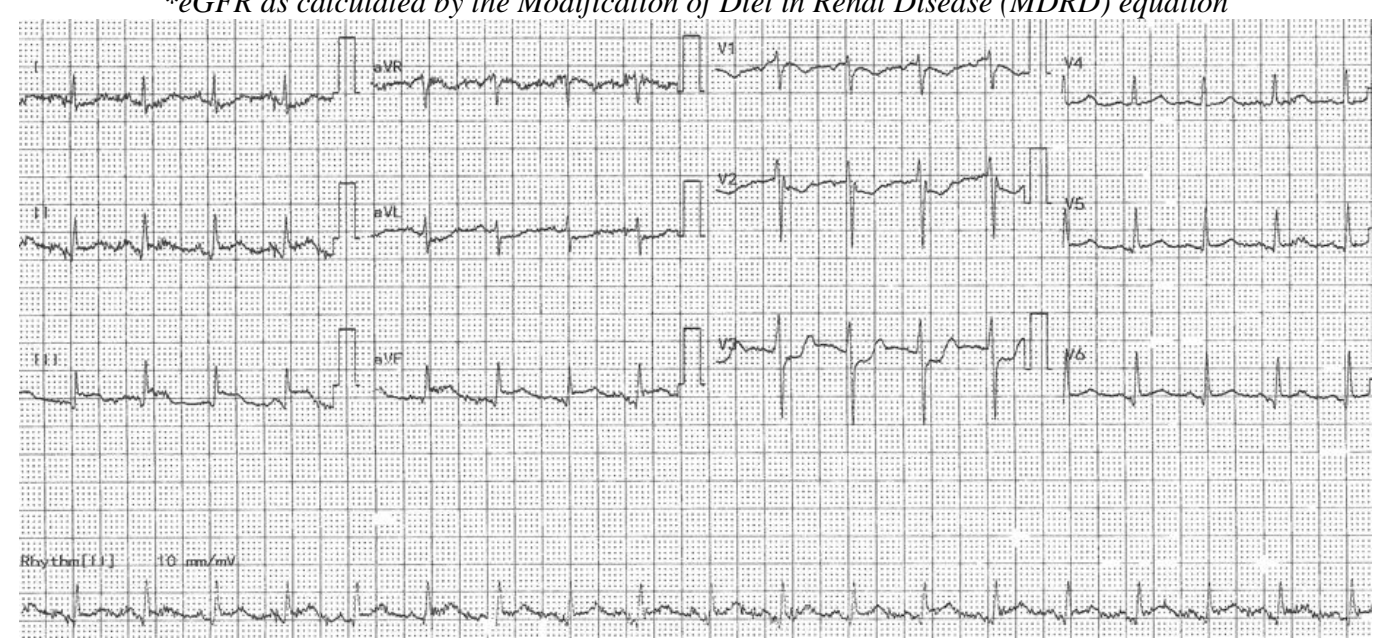

Figure 1: Admission electrocardiogram.

ST segment elevation is seen inferiorly (leads II, III, aVF $2 \mathrm{~mm}$ with 1-2mm in V5-6) with reciprocal ST depression changes seen in the septal chest leads (V2, V3). This pattern of changes is consistent with inferoposterior myocardial infarction.

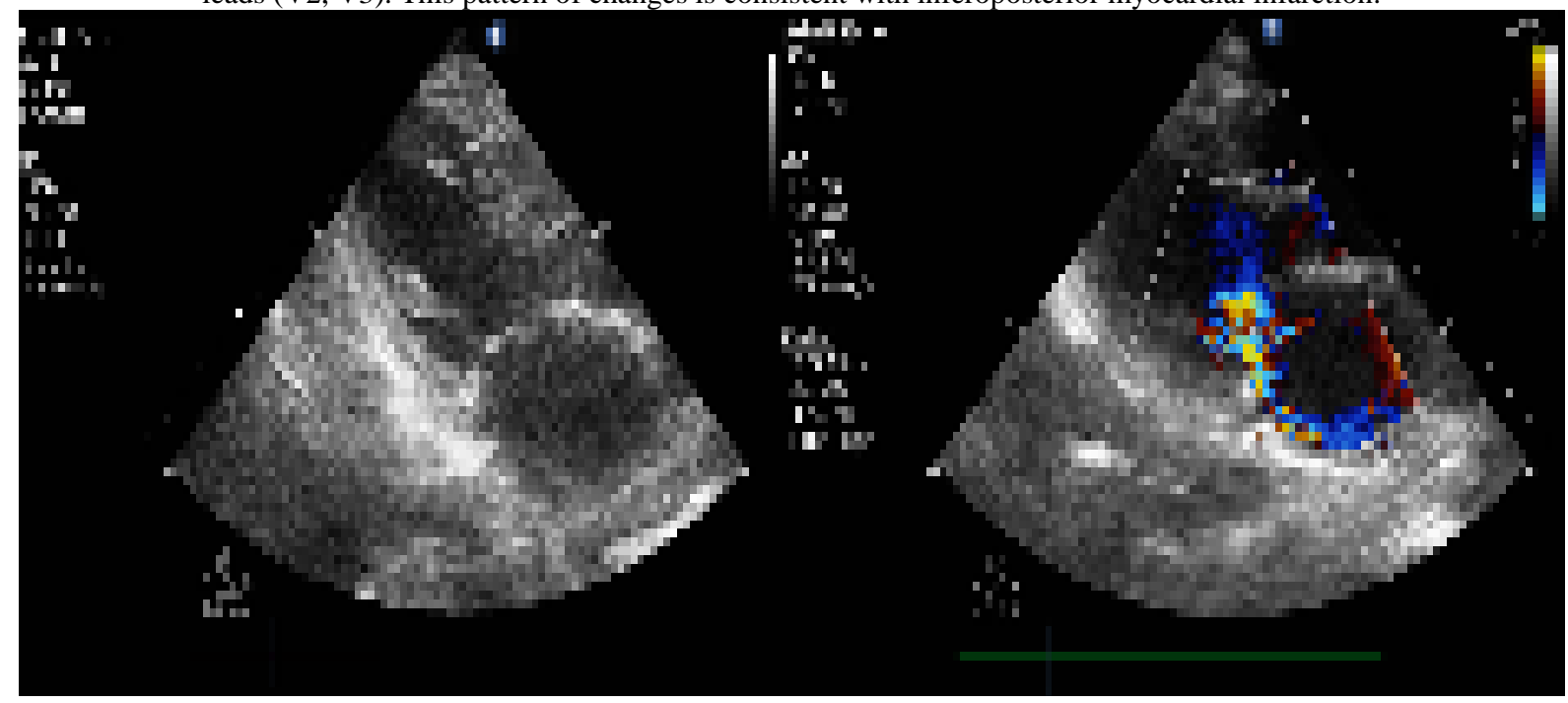

Figure 2: Admission echocardiogram.

Echocardiogram shows moderate left ventricular dysfunction with an ejection fraction of $40 \%$ although the left ventricle was not dilated. The inferolateral regions were akinetic and right ventricular impairment was seen. Moderate posteriorly directed eccentric jet of mitral regurgitation, due to restricted posterior mitral valve leaflet also noted as occurs in large inferolateral MI. 

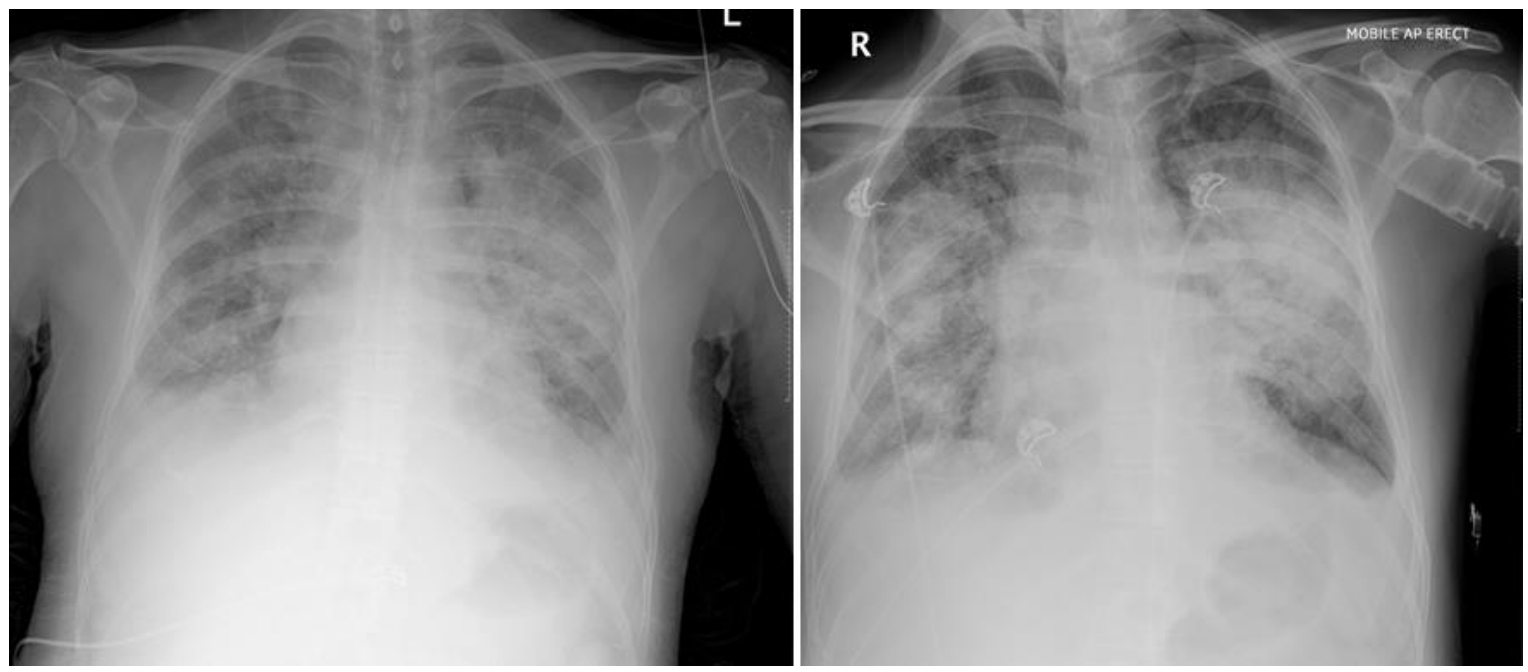

Figure 3: Chest radiograph

Bilateral infiltrates seen in both radiographs. This was initially interpreted as likely secondar to pulmonary oedema. Continuous positive airway pressure equipment is seen on the right image (day 2) and it was clear that there wis hilar sparing which is in keeping with bilateral pneumonitis rather than pulmonary oedema.

The patient was given $80 \mathrm{mg}$ of intravenous Furosemide and started on continuous positive airway pressure (CPAP) therapy due to type 1 respiratory failure. On review by the cardiologist a diagnosis of acute inferoposterior MI with RV involvement was made. The patient's case was discussed for primary percutaneous coronary intervention (PPCI) for which he was deemed unsuitable. The patient could not lie flat due to pulmonary oedema and the anaesthetists judged him to be unfit for intubation. There was also uncertainty on the timing of the MI due to the absence of chest pain. However, given that there was preserved $\mathrm{R}$ waves with no $\mathrm{Q}$ waves, this indicated a recent onset (Figure 1). He was subsequently treated with thrombolysis using Tenecteplase followed by an Unfractionated Heparin infusion. Acute pulmonary oedema caused by cardiac failure was deemed the cause of his severe hypoxia. However, atypical signs on the CXR and the lack of "wet" clinical features of pulmonary oedema, such as frothy sputum, aroused suspicion of COVID19 infection.

Owing to the patient's MI and severe right ventricular dysfunction it was reiterated here that he would not be a candidate for airway intubation nor ITU admission. This decision was challenged by two consultant cardiologists but five consultant intensivists agreed that given the pressures on expanded ITU beds due to the pandemic, the patient would not be suitable for admission.

The complex situation was conveyed to the patient's family with multiple conversations by telephone with his wife, son and brother. There was disbelief by the family that a previously fit man could become critically ill with multiorgan failure in such a short space of time and have such a dismal prognosis.

A COVID-19 swab was positive. His CXR showed improved pulmonary oedema, but clearer bilateral infiltrates with relative hilar sparing consistent with COVID-19 pneumonitis. He was randomised into the RECOVERY trial [5]. Given his inability to tolerate high CPAP pressures and concern he would become exhausted without mechanical ventilation he was rediscussed with ITU who still deemed him unsuitable for intubation. It became apparent that he would not survive his illness due to declining respiratory function causing exhaustion. Three days after admission, the patient's oxygen saturations deteriorated to $81 \%$ and his clinical status rapidly declined thereafter with the family being allowed to be with the patient for his final few hours of life.

\section{Discussion}

As this patient was not a candidate for PPCI, it is difficult to distinguish definitively between myocarditis and thrombotic sequelae secondary to COVID-19. The moderate rise and fall in troponin (Table 1) supports a diagnosis of myocarditis or a partial thrombotic occlusion. A localised ECG pattern fitting the impairment seen on echocardiogram favours the diagnosis of MI. The echocardiogram demonstrates an eccentric jet of mitral regurgitation from the tethered posterior mitral valve leaflet and a severely hypokinetic inferolateral wall. Both of these changes are often seen with inferolateral MI.

The literature on MI with right ventricular involvement in the context of COVID-19 is scarce. These MIs are associated with multi-organ failure and severe haemodynamic compromise due to a drop in left ventricular preload and cardiac output. Early coronary reperfusion and careful resuscitation with fluids and inotropes are key interventions, both of which may have been compromised with COVID-19. Whilst fluid therapy is a priority in cardiogenic shock, it may worsen respiratory function. Slow fluid therapy was chosen in our patient to prevent overloading the ventricles and worsening pulmonary oedema. Balancing the potential risks and benefits of fluid therapy requires regular assessment of fluid status [6]. Fluid assessment using typical methods may be complicated in septic COVID-19 patients. For instance, low blood pressure may not represent hypovolaemia, but instead a drop in total peripheral resistance through vasodilation [6].

Public fear of contracting COVID-19 in a clinical environment may have contributed to delayed clinical presentation. Health-service reorganisation, lack of clinical guidance and staff shortages were early challenges in the pandemic. Delayed cardiac presentation and healthcarerelated barriers to care may endure as the pandemic continues and strategies to optimise outcomes should be investigated.

The decision not to mechanically ventilate, intubate or offer PPCI in a young, previously healthy patient presents a challenging decision for clinicians. We are likely to see patients in similar scenarios; where a decision to establish an appropriate ceiling of care has to be made. Forming clinical frameworks to aid clinicians in making these decisions in the context of COVID-19 is important. 
Our patient's presentation demonstrated to our clinicians the challenges of COVID-19 at a time where the evidence base was still scarce. His allocation into the RECOVERY trial contributed to the understanding of steroid therapy in COVID-19. Our team and the medical community would extend our gratitude to this patient.

\section{Competing interest}

We have no competing interests to declare.

\section{Acknowledgements}

We have no acknowledgements to declare.

\section{Contributorship Statement}

SP, ZV, SSB and GPM planned the article. ZV and GPM sought permission from the next of kin. SP, ZV and SSB collected all data. SP and ZV drafted the manuscript. SP, ZV, SSB and GPM revised and redrafted the manuscript.

\section{Conflict of interests}

No conflict of interests.

\section{Funding statement}

There was no funding supporting for the completion of this work.

\section{Ethics approval}

No ethical approval was required.

\section{Consent}

As this patient passed away, we have obtained informed consent from his next of kin.

\section{Guarantor}

Susil Pallikadavath is the nominated guarantor of this manuscript.

\section{References}

1. Organization, T.W.H. (2020) COVID-19 Weekly Epidemiological Update: Data as received by WHO from national authorities as of 1 November 2020, 10am CEST.

2. Cardiology., T.E.S.f. (2020) ESC Guidance for the Diagnosis and Management of CV Disease during the COVID-19 Pandemic.

3. Zaim, S., et al., (2020) COVID-19 and Multiorgan Response. Curr Probl Cardiol. 45(8): p. 100618.

4. Poston, J.T. and J.L. Koyner. (2019) Sepsis associated acute kidney injury. BMJ. 364: p. k4891.

5. Horby, P., et al. (2020) Dexamethasone in Hospitalized Patients with Covid-19 - Preliminary Report. N Engl J Med.

6. Selby, N.M., et al. (2020) Covid-19 and acute kidney injury in hospital: summary of NICE guidelines. BMJ.369: p. m1963.
This work is licensed under Creative Commons Attribution 4.0 License
To Submit Your Article Click Here: Submit Manuscript

DOI: $10.31579 / 2692-9759 / 018$
Ready to submit your research? Choose Auctores and benefit from:

* fast, convenient online submission

* rigorous peer review by experienced research in your field

* rapid publication on acceptance

* authors retain copyrights

* unique DOI for all articles

* immediate, unrestricted online access

At Auctores, research is always in progress.

Learn more www.auctoresonline.org/journals/cardiology-research-andreports 